\title{
Ammonia-oxidizing archaea have similar power requirements indiverse marine oxic sediments
}

\author{
RUI ZHAO ${ }^{1}$, JOSE M. MOGOLLON ${ }^{2}$, DESIREE L. \\ ROERDINK ${ }^{3}$, INGUNN H THORSETH ${ }^{3}$, INGEBORG \\ ØKLAND ${ }^{3}$ AND STEFFEN LETH JØRGENSEN ${ }^{3}$ \\ ${ }^{1}$ University of Delaware \\ ${ }^{2}$ Leiden University \\ ${ }^{3}$ University of Bergen \\ Presenting Author: zhaorui087@gmail.com
}

Energy/power availability is regarded as the ultimate controlling factor of microbial abundance in the deep biosphere, where fewer cells were found in habitats of less energy availability. A critical assumption driving the proportional relationship between total cell abundance and power availability is that the cell-specific power requirement keeps constant or varies over smaller ranges than other variables, which has yet to be validated. Here we present a quantitative framework to determine the cell-specific power requirement of the omnipresent ammonia-oxidizing archaea (AOA) in eight sediment cores with 3-4 orders of magnitude variations of organic matter flux and oxygen penetration depths. Our results showed that despite the six orders of magnitude variations in the rates and power supply of nitrification and AOA abundances across these eight cores, the cell-specific power requirement of AOA from different cores and depths overlaps and varies in a narrow range of $10^{-18}-10^{-16} \mathrm{~W}$ cell $^{-1}$, where the lower end may represent the basal power requirement of microorganisms persisting in subseafloor sediments. In individual cores, AOA also exhibit similar cellspecific power requirement, regardless of the AOA population size or sediment depth/age. Such quantitative insights may lay a foundation for a first-order estimate of the standing stock of AOA in global marine sediments. 